\title{
Nuclear FABP7 immunoreactivity is preferentially expressed in infiltrative glioma and is associated with poor prognosis in EGFR-overexpressing glioblastoma
}

\author{
Yu Liang* ${ }^{* 1,2}$, Andrew W Bollen ${ }^{3}$, Ken D Aldape ${ }^{4}$ and Nalin Gupta ${ }^{1}$
}

Address: ${ }^{1}$ Department of Neurological Surgery, Brain Tumor Research Center, University of California, San Francisco, CA 94143, USA, ${ }^{2}$ Current address: Division of Molecular Biology, Sequence Detection System \& Arrays, Applied Biosystems, Foster City, CA 94404, USA, ${ }^{3}$ Department of Pathology, University of California, San Francisco, CA 94143, USA and ${ }^{4}$ Department of Pathology, Section of Neuropathology, University of Texas M. D. Anderson Cancer Center, Houston, TX 77030, USA

Email: Yu Liang* - liangy01@ @otmail.com; Andrew W Bollen - andrew.bollen@ucsf.edu; Ken D Aldape - kaldape@mdanderson.org; Nalin Gupta - GuptaN@neurosurg.ucsf.edu

* Corresponding author

Published: 19 April 2006

BMC Cancer 2006, 6:97 doi:10.1/86/147/-2407-6-97
Received: 05 November 2005

Accepted: 19 April 2006

This article is available from: http://www.biomedcentral.com/147I-2407/6/97

(C) 2006 Liang et al; licensee BioMed Central Ltd.

This is an Open Access article distributed under the terms of the Creative Commons Attribution License (http://creativecommons.org/licenses/by/2.0), which permits unrestricted use, distribution, and reproduction in any medium, provided the original work is properly cited.

\begin{abstract}
Background: We previously identified brain type fatty acid-binding protein (FABP7) as a prognostic marker for patients with glioblastoma (GBM). Increased expression of FABP7 is associated with reduced survival. To investigate possible molecular mechanisms underlying this association, we compared the expression and subcellular localization of FABP7 in non-tumor brain tissues with different types of glioma, and examined the expression of FABP7 and epidermal growth factor receptor (EGFR) in GBM tumors.

Methods: Expression of FABP7 in non-tumor brain and glioma specimens was examined using immunohistochemistry, and its correlation to the clinical behavior of the tumors was analyzed. We also analyzed the association between FABP7 and EGFR expression in different sets of GBM specimens using published DNA microarray datasets and semi-quantitative immunohistochemistry. In vitro migration was examined using SF763 glioma cell line.

Results: FABP7 was present in a unique population of glia in normal human brain, and its expression was increased in a subset of reactive astrocytes. FABP7 immunoreactivity in grade I pilocytic astrocytoma was predominantly cytoplasmic, whereas nuclear FABP7 was detected in other types of infiltrative glioma. Nuclear, not cytoplasmic, FABP7 immunoreactivity was associated with EGFR overexpression in GBM $(N=61, p=0.008)$. Expression of the FABP7 gene in GBM also correlated with the abundance of EGFR mRNA in our previous microarray analyses $(N=34, p=0.016)$ and an independent public microarray dataset $(N=28, p=0.03)$. Compared to those negative for both markers, nuclear FABP7-positive/EGFR-positive and nuclear FABP7-positive/EGFR-negative GBM tumors demonstrated shortest survival, whereas those only positive for EGFR had intermediate survival. EGFR activation increased nuclear FABP7 immunoreactivity in a glioma cell line in vitro, and inhibition of FABP7 expression suppressed EGF-induced glioma-cell migration. Our data suggested that in EGFR-positive GBM the presence of nuclear FABP7 immunoreactivity increases the risk of poor prognosis

Conclusion: In this study, we identified a possible mechanism as the basis of the association between nuclear FABP7 and poor prognosis of GBM. FABP7 expression can be found in all grades of astrocytoma, but neoplastic cells with nuclear FABP7 were only seen in infiltrative types of tumors. Nuclear FABP7 may be induced by EGFR activation to promote migration of GBM tumor cells. Positive nuclear FABP7 and EGFR overexpression correlated with short survival in EGFR-positive GBM patients. Therefore, nuclear FABP7 immunoreactivity could be used to monitor the progression of EGFR-overexpressed GBM.
\end{abstract}




\section{Background}

GBM is the highest grade of astrocytoma and is also the most common primary brain tumor in adults. Approximately $50 \%$ of patients with GBM die within a year of diagnosis, despite the use of many aggressive treatment approaches [1]. Lack of reliable prognostic markers for these patients is a hindrance to improving therapy and individualizing therapeutic interventions. Amplification and/or overexpression of the EGFR gene, mutation of the p53 gene, and proliferation indices have all been proposed to predict survival of patients with GBM and to play a role in the pathophysiology of their tumors [2,3]; however, other studies have shown no such association with outcome [4-6]. One reason for this discrepancy is that strong clinical factors such as patient age need to be included [7,8]. Although clinical parameters such as age, Karnofsky performance status at diagnosis, and extent of resection are routinely used in clinical practice to predict the outcome of patients with GBM, none of these variables have a direct connection with tumor pathogenesis.

In a previous study, gene expression profiling of a group of GBM specimens identified a cluster of about 50 named genes whose expression was inversely associated with survival [9]. In examining the annotations of "biological process" in the Gene Ontology terms for each gene [10], the annotation "neurogenesis" appeared most frequently, suggesting a common role for these genes in central nervous system development. In contrast, a number of other annotations for biological process such as "cell proliferation," "inflammatory response," and "immune response" were underrepresented in these genes. Because several of these genes are involved in cell-cell and cell-matrix interactions and cell migration, we hypothesized that their increased expression might be related to more infiltrative and aggressive tumor behavior. Based on the results of the preceding analyses and the availability of antibodies, we chose to investigate the prognostic value of one gene, FABP7, in greater detail [9].

Although FABP7 is a cytoplasmic protein, its varying subcellular localization between nucleus and cytoplasm has been reported in developing brain [11], glioma cell lines [12], and GBM specimens [9]. Increased FABP7 expression was also found in glia following nerve injury $[13,14]$. We separately scored FABP7 immunoreactivity in nucleus and cytoplasm, and found that nuclear FABP7 immunoreactivity was inversely correlated with survival of patients with GBM, particularly in younger cases [9]. This result is consistent with other reports that emphasize the effect of age upon various prognostic factors $[7,8]$, and such a pattern is similar to a recent finding of an association between EGFR overexpression and poor prognosis in younger GBM patients [7].
FABP7 is a member of the multi-gene fatty acid-binding protein (FABP) family and binds to very-long-chain polyunsaturated fatty acids $(\mathrm{C}>16)$ such as docosahexaenoic acid (DHA) with very high affinity in vitro [15]. FABP7 appears to have different roles in different tissue types. It is highly expressed in radial and Bergmann glial cells throughout the developing central nervous system and gradually declines in the adult $[16,17]$. FABP7 is required for neuron-induced glial differentiation and subsequent migration of neurons along the glial processes, but has no effect on cell proliferation and adhesion [11]. In Schwann cells, FABP7 expression is downstream of the Ras-independent EGFR signaling pathway, and it regulates interactions between Schwann cells and axons in normal peripheral nerves and peripheral nerve tumors without affecting cell proliferation and migration [13]. Differential expression of different types of FABPs is found in several types of tumors and their normal-cell counterparts, and FABPs have been shown to modulate growth and differentiation of normal and neoplastic cells [18]. FABP7 was also shown to induce mammary differentiation and to mediate growth inhibition of breast cancer cells $[19,20]$.

It has been suggested that FABPs increase the solubility of fatty acids in the cytoplasm when transporting fatty acids between membrane compartments, and bring fatty acids to their nuclear targets [21]. In addition, subcellular localization of FABPs appears to be tissue specific and closely associated with gene expression and function. Liver-type FABP targets fatty acids to the nucleus and interacts with peroxisome proliferator-activated receptors $\alpha$ and $\gamma$ to regulate gene expression [22-24]. Soluble FABP7 was found to induce differentiation of the mammary gland in mice [20]. FABP7 is present in both the nucleus and cytoplasm in glial cells, as well as in the conditioned media of glial cells in culture [11], but is found only in the cytoplasm of Kupffer cells in the liver [25].

In this study, we examined the expression patterns and subcellular localization of FABP7 in specimens from normal individuals, from individuals with gliosis only, and from patients with gliomas differing in grade and histology. We also used independent sets of GBM specimens to analyze the relationship of subcellular localization of FABP7 with patient outcome and EGFR expression, and to seek possible mechanisms underlying the functions of FABP7 in GBM.

\section{Methods \\ Cell culture}

Glioma cell lines were obtained from the Neurosurgery Tissue Bank at the University of California, San Francisco. Immortalized human astrocytes were provided by Dr. Russ Pieper (University of California, San Francisco) [26]. 
All cells were maintained in Eagle's minimal essential medium with $10 \% \mathrm{FBS}$ and $5 \% \mathrm{CO}_{2}$.

\section{Tissue specimens}

Frozen and paraffin-embedded specimens were obtained from the Neurosurgery Tissue Bank at the University of California, San Francisco, and University of Texas, M. D. Anderson Cancer Center after approval from the Committee on Human Research. Tissue sections for immunohistochemistry were of $5 \mu \mathrm{m}$ in thickness. Gliotic and normal brain tissues were obtained from epileptic patients and postmortem specimens, respectively. Clinical data of patients with primary GBM that were used for analyzing the correlation between FABP7 and EGFR immunoreactivity are summarized in Tables 2 and 4. Two cohorts of GBM patients (61 and 44 cases, respectively) for EGFR expression analysis are the same sets used in a previous study [9].

\section{Antibodies}

FABP7-specific polyclonal antibodies were gifts from Drs. N. Heintz (Rockefeller University, New York, NY) and R. Godbout (University of Alberta, Alberta, Canada). Antibodies from both sources produced similar staining patterns and specificity on Western blots and immunohistochemistry using GBM specimens ([12] and data not shown). A dilution of 1 to 400 was used for both immunostaining and migration assays, and a dilution of 1 to 500 was used for immunoblotting; secondary antibodies alone did not show detectable signal. Dilution of antibodies against glial fibrillary acidic protein (GFAP) (ICN; Costa Mesa, CA) and EGFR (clone F4; Sigma, St. Louis, MO) for immunohistochemistry was 1:1000 and 1:400, respectively. Peroxidase-conjugated and biotinylated secondary antibodies were obtained from Vector Laboratories (Burlingame, CA). Fluorescine-conjugated and Rhodamine-conjugated secondary antibodies and normal rabbit serum were obtained from Jackson ImmunoResearch Laboratories (West Grove, PA).

\section{Western blot analysis}

Total RNA was extracted from frozen tissues specimens using Trizol (Invitrogen; Carlsbad, CA) as described previously [9], and genomic DNA was removed from the interphase and organic phase by ethanol precipitation. The protein fraction was then purified by isopropanol precipitation, washed several times in $0.3 \mathrm{M}$ guanidine hydrochloride in 95\% ethanol, and resuspended in 1\% SDS. The protein concentration of each sample was quantitated by using a $\mathrm{D}_{\mathrm{c}}$ Protein Assay Kit (Bio-Rad; Hercules, CA), and equal amounts of protein for each sample were separated by SDS-PAGE and transferred to nitrocellulose membranes (Bio-Rad), blocked with 10\% skim milk, incubated with specific antibodies, and visualized using a
Super Signal West Pico Chemiluminescent kit (Pierce; Rockford, IL).

\section{Immunohistochemistry}

All frozen tissue sections used for immunohistochemistry were fixed in $4 \%$ formaldehyde, treated with $\mathrm{H}_{2} \mathrm{O}_{2}$, blocked with normal serum, incubated with primary antibodies at $4{ }^{\circ} \mathrm{C}$ overnight or room temperature (RT) 2 hours, incubated with biotinylated secondary antibody and peroxidase-labeled streptavidin at RT for $30 \mathrm{~min}$, to visualize the immunoreactivity with the DAB Reagent kit (KPL; Gaithersburg, MA). Staining of paraffin-embedded sections followed the same protocol, except for prior dewaxing and antigen retrieval by microwave heating. Immunostaining and semi-quantitative scoring of p53 and EGFR expression were performed as previously described [7].

SF763 glioma cells were plated and incubated overnight in Lab-Tek chamber slides (Nalge Nunc International; Rochester, NY) followed by 24 hours of $0.5 \%$ serum starvation and 2 days of $50 \mathrm{ng} / \mathrm{ml} \mathrm{EGF} \mathrm{(Invitrogen)} \mathrm{treat-}$ ment. After fixation in 4\% formaldehyde, cells were blocked with normal serum, followed by 2 hours of RT incubation with the primary antibody and 1 hour of RT incubation with the secondary antibody. Cells were then covered with Vectashield (Vector Laboratories) to prevent fading of fluorescence. The fluorescence intensity of 200 control or EGF-treated cells was digitally recorded and the ratios were calculated.

\section{Antisense inhibition and migration assay}

Antisense oligodeoxynucleotides (ODNs) used were complementary to the position -13 to 7 of the FABP7 cDNA, and sense ODNs complementary to the same region were used as a control. The first 3 and the last 3 phosphodiester bonds on the ODNs were modified to phosphorothioate bonds to prevent degradation. SF763 glioma cells were serum-starved in $0.5 \%$ serum-containing medium for 24 hours, followed by 2 days of $50 \mathrm{ng} / \mathrm{ml}$ EGF treatment in the same low-serum media. Control cells were maintained in the low-serum medium for 2 days. ODNs were incubated with FuGene (Roche, Basel, Switzerland) at RT for $30 \mathrm{~min}$, and then added to SF763 cells on the second day of EGF treatment to a final concentration of $100 \mathrm{nM}$.

The inserts of TransWell chambers (Corning, Corning, NY) with $5 \mu \mathrm{m}$ pores were incubated with $100 \mu \mathrm{g} / \mathrm{ml}$ of rat-tail type 1 collagen (BD Biosciences, San Jose, CA) overnight at room temperature, and washed with phosphate-buffered saline (PBS). At the end of the 2-day EGF treatment, cells were dislodged using $2 \mathrm{mM}$ EDTA in PBS and then resuspended in the same treatment media as before (control or EGF, sense or antisense ODNs). Lowserum medium was placed in the bottom well, and $1 \times 10^{4}$ 


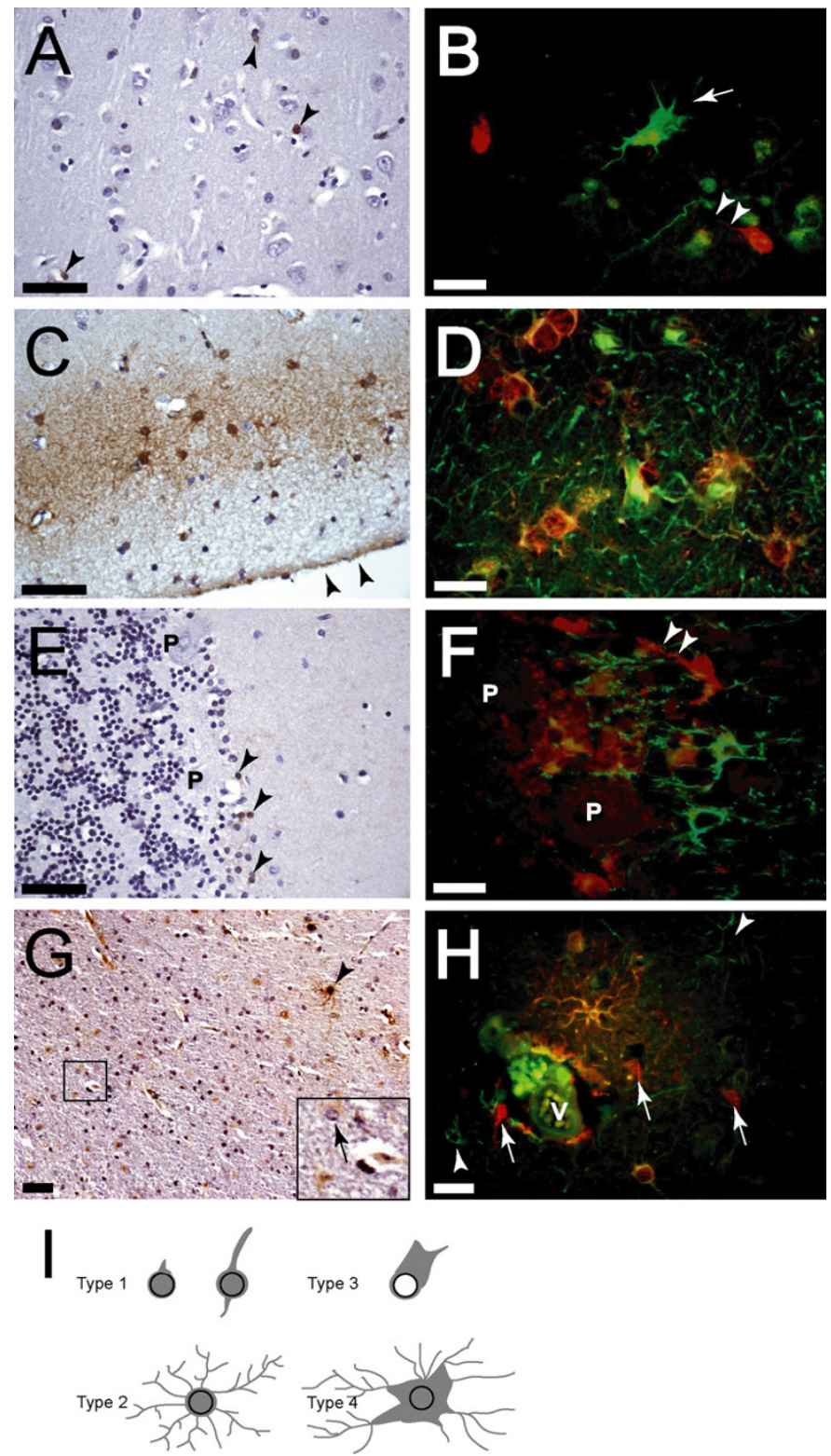

Figure I

Several groups of glial cells in adult normal and gliotic brains expressed FABP7. A, scattered FABP7-positive Type I cells (arrowheads) were detected in normal cerebral cortex. Nuclei of these cells were irregular or elongated, and appeared to be larger than those of oligodendrocytes. B, FABP7-positive Type I cells usually had only one or two processes (arrowheads), and were distinctive from GFAP-expressing astrocytes bearing elaborate processes (arrow). C and D, all FABP7-positive Type 2 cells localized at the subpial layer had numerous processes and expressed GFAP. Arrowheads in $C$ indicate pia. Some GFAP+/ FABP7- astrocytes could be seen. $E$, scattered FABP7-positive Type I cells were detected in normal cerebellum (arrowheads), whereas granule cells and Purkinje cells (P) were FABP7 negative. F, FABP7 and GFAP staining identified two distinctive populations of astrocytes. Arrowheads indicate the process of a FABP7-positive Type I cell. G, the number of FABP7-positive cells was increased in gliotic tissues, and Types 3 (arrow in inset) and 4 (arrowhead) cells appeared. $H$, in a region of perivascular gliosis, several GFAP+/FABP+ reactive astrocytes (Type 4) were seen. There were also FABP7-negative reactive astrocytes (arrowheads) and Type I cells (arrows) in this region. Strong immunofluorescence inside the vessel (V) was autofluorescence. $I$ is a schematic summary of the morphology of the four types of glial cells identified in normal and gliotic adult brains. Gray color indicates FABP7 immunoreactivity. Note that Type 3 cells have gemistocytic characteristics and usually do not have nuclear FABP7. Bars in $A, C, E, G, 50 \mu \mathrm{m}$; bars in $B, D, F, H, 20 \mu \mathrm{m}$, and red and green fluorescence represents FABP7 and GFAP, respectively. 
cells were plated into each insert. After 4 hours, unmigrated cells were removed with cotton swabs and migrated cells were fixed and stained using a HEMA 3 stain set (Fisher Diagnostics, Middletown, VA). For each insert, cell numbers were counted from five randomly chosen fields under $200 \times$ magnification.

\section{Data analysis}

All statistical analyses used SPSS for Windows (Release 11.5.0). The fluorescence intensity recorded using the Openlab software (Improvision, Lexington, MA) and migration data were analyzed using Student's t test. Correlation of nuclear localization of FABP7 with patient survival was analyzed using the Cox proportional hazards regression. Hazard ratios provide information about the direction of an association (a numeral over 1 indicates an increased risk with the positive variable, and a numeral under 1 indicates a decreased risk) as well as the magnitude of the risk. To evaluate the relationship between nuclear FABP7 and EGFR upon patient survival, new variables were used to divide patients into four groups based on the immunoreactivity of nuclear FABP7 and EGFR of their tumors: dual negative as "0", nuclear FABP7-negative/EGFR-positive as "1", nuclear FABP7-positive/EGFRnegative as " 2 ", and dual positive as " 3 ". Bivariate correlations were evaluated by the Spearman test. A p value < 0.05 was considered statistically significant for all tests.

\section{Results}

Differential glial fibrillary acidic protein immunoreactivity identifies four subsets of fatty acid-binding protein 7expressing cells in adult normal and gliotic brain tissues

We compared expression and subcellular localization of FABP7 in adult normal and gliotic brain specimens using immunohistochemistry. In normal cerebrum, there was minimal FABP7 reactivity in the white matter (data not shown), and only scattered, predominantly nuclear FABP7 immunoreactivity in the cortex (Fig. 1A). Morphologically, the positive cells appeared to be glial in origin but were negative for GFAP. These cells had a thin rim of cytoplasm with no processes or with much fewer processes than their GFAP-positive counterparts (Fig. 1B). For purpose of comparison, we named this unique group of cells Type 1 cells. A separate population of GFAP-positive cells in the subpial layer was also found to be positive for FABP7 (Fig. 1C and 1D). We designated these cells Type 2 cells; these were distinguishable from Type 1 cells by their location, elaborate processes, GFAP immunoreactivity, and FABP7 staining throughout their nucleus, cytoplasm, and processes. The presence of Type 2 cells in the subpial layer is consistent with a previous finding in which FABP7 mRNA was found in the glia limitans of adult mice [27]. Endothelial cells and neurons were negative for FABP7 expression (Fig. 1A, and additional data not shown). In the cerebellum, only scattered FABP7-positive glial cells were identified, mostly in region of the Purkinje cell layer (Fig. 1E), which is also in agreement with a previous in situ hybridization study in mice [27]. These positive cells were very similar to the Type 1 cells we identified in cerebral cortex (Fig. 1F).

The expression of FABP7 and the number of FABP7-positive cells were increased in the cortex of gliotic brain specimens, although the subcellular localization of FABP7 was variable (Fig. 1G). In addition to the Type 1 cells, two distinct types of FABP7-positive cells, designated as Type 3 and Type 4 cells, were identified in gliotic cerebral cortex, and were probably reactive astrocytes. Type 3 cells showed FABP7 immunoreactivity mainly in their gemistocytic cytoplasm, while nuclear staining was absent (Fig. 1G, inset). Type 4 cells featured hypertrophic cytoplasm and elaborate processes, and their nucleus, cytoplasm, and processes are strongly positive for FABP7 (Fig. 1G). Both Type 3 and Type 4 cells expressed GFAP (Fig. 1H), and were not found in normal cerebral cortex, but only a subset of reactive astrocytes expressed FABP7 (Fig. 1H). Another feature in gliotic brain specimens was that FABP7 was weakly positive in the cytoplasm of some neurons (data not shown). Figure 1I summarizes the morphology of the four types of FABP7-expressing glial cells described above.

\section{Nuclear fatty acid-binding protein 7 is detected in neoplastic astrocytes in infiltrative types of glioma but not in grade I pilocytic astrocytoma}

Because FABP7 demonstrates increased expression and variable subcellular localization in a subset of reactive astrocytes but not in most oligodendrocytes, we determined whether FABP7 is universally expressed in different grades of astrocytoma. For comparison, we also examined specimens from oligoastrocytoma (OAC) and oligodendroglioma (ODG).

An immunoblot of extracts from two GBM specimens and two oligodendroglial tumors showed detectable levels of FABP7 protein (Fig. 2A). We found that 1 of 5 grade II astrocytoma specimens and 3 of 5 grade III astrocytoma specimens were positive for FABP7. Paralleling the results obtained from GBM specimens [9], both nuclear and cytoplasmic FABP7 immunoreactivity was found in these tumors (Fig. 2B and 2C). FABP7-positive reactive astrocytes similar in morphology to the Types 3 and 4 cells (data not shown) were observed occasionally. We also examined 10 pilocytic astrocytoma specimens (grade I), and, in agreement with previous gene expression profiling of this type of tumor [28], 9 of our specimens were positive for FABP7. Interestingly, the FABP7 immunoreactivity in these 9 cases was predominantly in the cytoplasm and cell processes, not in the nuclei (Fig. 2D). The presence of nuclear FABP7 immunoreactivity in grades II, III, and IV 


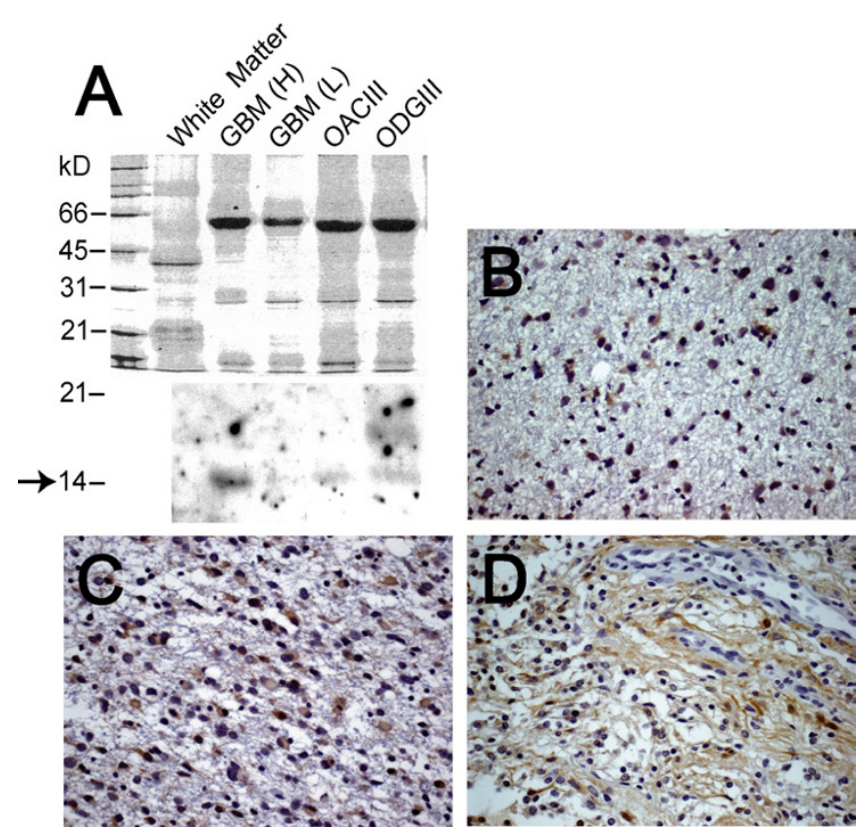

Figure 2

FABP7 was detected in all grades of astrocytomas. A, lower, expression of FABP7 was analyzed Western blotting using lysate from normal white matter, two GBM specimens $(H$ and $L$ indicate high and low, respectively (high and low FABP7 expression based on the results of the previous microarray study [9]), one oligoastrocytoma grade III (OACIII), and one oligodendroglioma grade III (ODGIII); upper, the protein loading was demonstrated by Coomassie Blue staining. The arrow indicates the size of the FABP7 core protein. The $14 \mathrm{kD}$ band in GBM (L) appeared after longer exposure of the film. The $18 \mathrm{kD}$ band that appeared in the ODGIII lysate may not be non-specific, since several immunoreactive bands in that region could also be detected in lysate from a panel of glioma cell lines (data not shown). Representative photomicrographs of immunohistochemistry of FABP7 in grade II astrocytoma $(B)$, grade III anaplastic astrocytoma $(C)$, and grade I pilocytic astrocytoma $(D)$ demonstrated distinctive FABP7 immunoreactivity in the cytoplasm and cell processes in pilocytic astrocytomas as opposed to the nuclear and cytoplasmic staining in grades II and III astrocytomas. FABP7-positive nuclei that were occasionally detected resembled the Type I cells seen in normal brain. The scale of the photomicrographs is the same as in Figure I A.

astrocytoma specimens was statistically significant when compared to grade I pilocytic astrocytoma (Table 1).

Among 19 grade III ODG specimens examined, FABP7 immunoreactivity was seen mostly in cells that were morphologically similar to Types 3 and 4 cells (Fig. 3A and 3B) and appeared to be reactive astrocytes. Neoplastic oligodendrocytes did not express FABP7. Similar to gliotic brain tissue, only a fraction of reactive astrocytes marked by GFAP staining expressed FABP7. FABP7 could also be detected in the nuclei and cytoplasm of microgemistocytes in some ODG specimens (Fig. 3C and 3D). Microgemistocytes are a group of neoplastic cells with eosinophilic cytoplasm and GFAP immunoreactivity that are sometimes present in ODG; however, half of our specimens ( 3 of 6 ) that contained GFAP-positive microgemistocytes did not express appreciable amounts of FABP7 (Fig. 3E and 3F). We found both cytoplasmic and nuclear FABP7 immunoreactivity present in 4 of 7 grade II (Fig. $3 \mathrm{G}$ ) and 8 of 10 grade III OAC specimens (Fig. $3 \mathrm{H}$ ), and those FABP7-immunoreactive specimens were also positive for GFAP (data not shown).

\section{Nuclear fatty acid-binding protein 7 in glioblastoma is associated with epidermal growth factor receptor overexpression}

Increased immunoreactivity of nuclear FABP7 correlated with poor prognosis of GBM, particularly in younger patients [9], and we sought to identify the molecular mechanism underlying this association by investigating EGFR expression in this tumor type.

EGFR expression evaluated by immunohistochemistry using a group of primary GBM specimens from 61 patients (Table 2) showed a trend toward a negative association with survival ( $\mathrm{p}=0.074)$, which was marginally correlated only in younger patients (less than the median age of 53 years; $\mathrm{p}=0.037$, hazard ratio $=1.819,95 \% \mathrm{CI}$ $1.036-3.195)$ but not in the old ones $(\mathrm{p}=0.875)$, consistent with the previous finding [7]. Since we noted a similar trend for nuclear FABP7 staining in this same set of specimens [9], it raised the possibility of a correlation between EGFR expression and nuclear FABP7. Indeed, EGFR expression correlated with nuclear FABP7 $(\mathrm{p}=0.008)$ but not with cytoplasmic FABP7 ( $\mathrm{p}=0.547)$ in this set of specimens. This finding is consistent with a detailed examination of FABP7/EGFR dual-positive GBM specimens with separate regions of nuclear and cytoplasmic FABP7 immunoreactivity. We found that if a cluster of tumor cells had only cytoplasmic FABP7 immunoreactivity, the EGFR staining was minimal (Fig. 4A and 4B). In contrast, when neoplastic cells in another region of the same tumor had nuclear FABP7 immunoreactivity, the EGFR immunoreactivity was usually prominent (Fig. 4C and 4D). The significant association between nuclear FABP7 and EGFR immunoreactivity seemed to be present only when the entire population, not specific age group, was analyzed, since the correlation was greatly reduced in both younger $(\mathrm{p}=0.048, \mathrm{~N}=31)$ and older groups $(\mathrm{p}=0.055, \mathrm{~N}=27)$ divided by the median age ( 53 years) of the cases.

The link between EGFR and nuclear FABP7 appeared to be specific for the neoplastic cells in GBM since nuclear FABP7 immunoreactivity did not co-exist with EGFR 
Table I: Summary of subcellular localization of fatty acid binding protein $\mathbf{7}$ in gliomas

\begin{tabular}{|c|c|c|c|c|c|}
\hline Diagnosis & $\begin{array}{c}\text { Total Number } \\
\text { examined }\end{array}$ & $\begin{array}{c}\text { nuclear only or } \\
\text { nuclear/cytoplasmic } \\
\text { positive }\end{array}$ & $\begin{array}{l}\text { Cytoplasmic positive } \\
\text { only }\end{array}$ & negative & $P$ value ${ }^{1}$ \\
\hline $\begin{array}{l}\text { grade I pilocytic } \\
\text { astrocytoma }\end{array}$ & 10 & 0 & 9 & I & $\mathrm{NA}^{2}$ \\
\hline grade II astrocytoma & 5 & I & 0 & 4 & 0.003 \\
\hline grade III astrocytoma & 5 & 3 & 0 & 2 & 0.001 \\
\hline grade IV GBM & 9 & 3 & 3 & 3 & 0.022 \\
\hline $\begin{array}{c}\text { grade II } \\
\text { oligoastrocytoma }\end{array}$ & 7 & 2 & 2 & 3 & 0.027 \\
\hline $\begin{array}{l}\text { grade III } \\
\text { oligoastrocytoma }\end{array}$ & 10 & 5 & 3 & 2 & 0.006 \\
\hline $\begin{array}{l}\text { grade III } \\
\text { oligodendroglioma }\end{array}$ & 19 & 3 & 0 & 16 & $N A^{3}$ \\
\hline
\end{tabular}

\footnotetext{
I The significance of nuclear FABP7 between 9 FABP7-positive grade I pilocytic astrocytoma specimens and the other type of FABP7-positive tumors was evaluated using Mann-Whitney test.

2 Minimal number of FABP7-positive nuclei were occasionally seen in all grade I tumors and we did not consider them for statistics.

${ }^{3}$ FABP7 was not expressed in neoplastic oligodendrocytes.
}

expression in several other types of specimens (data not shown). These were: (1) FABP7-positive microgemistocytes in ODG, (2) FABP7-positive reactive astrocytes in morphologically normal brain regions surrounding the EGFR-positive GBM, (3) FABP7-positive reactive astrocytes in gliotic tissues, and (4) Type 1 cells in normal cerebrum. Likewise, EGFR-positive cells surrounding the EGFR-overexpressing GBM that morphologically resembled reactive astrocytes did not show FABP7 immunoreactivity (data not shown).

We further examined whether the association between nuclear FABP7 and EGFR expression is reflected on the transcription level of both genes in two independent published DNA microarray datasets (Table 3). Among the 34 GBM specimens analyzed by oligonucleotide microarrays [29], mRNA expression of both FABP7 and EGFR genes moderately correlated with each other (Fig. 5A, p = $0.016)$. In another report using 28 GBM specimens with the same microarray system [30], expression of both genes once again correlated with each other (Fig. 5B, p = 0.03). This observation is in agreement with the marginal correlation between EGFR and the combination of both nuclear and cytoplasmic FABP7 immunoreactivity in our 61 specimens $(\mathrm{p}=0.033)$.

The presence of nuclear FABP7 immunoreactivity in EGFRexpressing GBM specimens is associated with shorter survival compared to those negative for nuclear FABP7

In our 61 GBM specimens poor survival was associated with increased nuclear FABP7 immunoreactivity as well as EGFR expression. Our data also showed that expression of FABP7 gene and nuclear FABP7 immunoreactivity correlated with mRNA and protein expressed by EGFR, respectively. Therefore, we hypothesized that nuclear FABP7 and
EGFR expression might have additive association with poor prognosis.

We examined the association of nuclear FABP7 with patient survival in relation to the EGFR expression in the 55 cases (Table 2) that had all parameters available using newly designated variables as defined in Methods: dual negative as " 0 ", nuclear FABP7-negative/EGFR-positive as "1", nuclear FABP7-positive/EGFR-negative as "2", and dual positive as " 3 ". Cox regression analysis of these cases (category 1 had only 4 cases and thereby was excluded) showed that, although nuclear FABP7-positive tumors (combining categories 2 and 3) demonstrated negative association with survival ( $\mathrm{p}=0.022$, hazard ratio $=1.408$, 95\% CI 1.05-1.888), the survival curves between specimens of the categories 2 and 3 were indistinguishable (Figure 6A, p = 0.509). However, we could not determine the interaction between EGFR expression and nuclear FABP7 immunoreactivity in the survival of GBM patients since there were no enough cases from category 1 .

We analyzed another group of 44 GBM specimens used in our earlier study [9] that had more category 1 specimens $(\mathrm{N}=12$, Table 4$)$. Consistent with what was observed in the previous set, cases from categories 2 and 3 together had significantly shorter survival compared to those of category $0(\mathrm{p}=0.001$, hazard ratio $=5.604,95 \% \mathrm{CI}$ 1.985-15.821), but showed no difference from each other (Figure 6B, p = 0.692). Cox regression analysis showed that the category 1 cases had shorter survival than immuno-negative tumors but better prognosis compared to the category 3 specimens $(\mathrm{p}=0.009$, hazard ratio $=$ 4.167 , 95\% CI 1.421-12.222), suggesting that detection of nuclear FABP7 immunoreactivity might predict poor prognosis for EGFR-positive GBM. 
Table 2: A set of 6 I GBM specimens for analyses of patient survival and the correlation between FABP7 and EGFR expression

\begin{tabular}{|c|c|c|c|c|c|c|c|c|c|c|}
\hline Case \# & Diagnosis & Age & $\begin{array}{c}\text { Survival } \\
\text { (wk) }\end{array}$ & Censor & FABP7 Nu & $\begin{array}{c}\text { FABP7 } \\
\text { Cyto }\end{array}$ & $\begin{array}{c}\text { New } \\
\text { Category* }\end{array}$ & EGFR IHC & P53 IHC & MIB-I \\
\hline 160 & GBM & 29 & 253 & I & 0 & 0 & 0 & 0 & 0 & 16.3 \\
\hline 381 & GBM & 32 & 220 & I & 0 & 0 & 0 & 0 & 3 & 32.6 \\
\hline 259 & GBM & 35 & 412 & I & 0 & 2 & 0 & 0 & 3 & 5.9 \\
\hline 495 & GBM & 38 & 125 & I & 0 & 2 & 0 & 0 & 3 & 2.2 \\
\hline 262 & GBM & 39 & $75.57 \mid$ & I & 0 & I & 0 & 0 & 3 & 12.7 \\
\hline 322 & GBM & 40 & 33.571 & I & 0 & 0 & 0 & 0 & 3 & 14.7 \\
\hline 483 & GBM & 41 & 18.4286 & I & 0 & 1 & 0 & 0 & 1 & 6.2 \\
\hline 499 & GBM & 43 & 26.143 & I & 0 & 0 & I & 2 & I & 10.8 \\
\hline 198 & GBM & 43 & 83 & I & 0 & I & 0 & 0 & 3 & 32.7 \\
\hline 310 & GBM & 43 & 66.143 & I & 0 & 2 & 0 & 0 & 0 & 33.6 \\
\hline 307 & GBM & 44 & 65.4286 & I & 0 & 1 & 0 & 0 & 3 & 29.1 \\
\hline 497 & GBM & 44 & 138.429 & I & 0 & 1 & 0 & 0 & 0 & 62.1 \\
\hline 436 & GBM & 45 & 151.286 & I & 0 & 0 & 0 & 0 & I & 6.6 \\
\hline 212 & GBM & 46 & $|06.57|$ & I & 0 & 0 & 0 & 0 & 2 & 39.6 \\
\hline 208 & GBM & 49 & 68.429 & I & 0 & I & 0 & 0 & 1 & 23.1 \\
\hline 8 & GBM & 52 & 45.429 & I & 0 & 2 & I & I & I & 5.9 \\
\hline 501 & GBM & 53 & II5.57| & I & 0 & 0 & 0 & 0 & 3 & 47.5 \\
\hline 330 & GBM & 53 & $20.7 \mid 43$ & I & 0 & 1 & 0 & 0 & 2 & 36.5 \\
\hline 446 & GBM & 56 & 4I.57I & I & 0 & 0 & 0 & 0 & 3 & 39.2 \\
\hline 404 & GBM & 56 & 68.857 & I & 0 & 2 & 0 & 0 & 3 & 36.1 \\
\hline 288 & GBM & 57 & 38.2 & I & 0 & 0 & I & I & 2 & 21.8 \\
\hline 19 & GBM & 58 & 80.429 & I & 0 & 2 & 0 & 0 & 3 & 6.1 \\
\hline 292 & GBM & 58 & 38.2 & I & 0 & 2 & NA & NA & 0 & NA \\
\hline 472 & GBM & 60 & 36.714 & I & 0 & 0 & 0 & 0 & 0 & 52.6 \\
\hline 286 & GBM & 61 & 51.286 & I & 0 & 2 & 0 & 0 & I & 51.3 \\
\hline 341 & GBM & 61 & 39.286 & I & 0 & 2 & 0 & 0 & 3 & 75.2 \\
\hline 135 & GBM & 63 & 21.143 & I & 0 & 2 & 0 & 0 & 1 & 44.6 \\
\hline 494 & GBM & 63 & 47.2 & I & 0 & 2 & I & I & NA & NA \\
\hline 426 & GBM & 64 & 83.143 & I & 0 & 2 & 0 & 0 & 3 & 34.6 \\
\hline 295 & GBM & 65 & 58.429 & I & 0 & 2 & 0 & 0 & 3 & 22.1 \\
\hline 260 & GBM & 67 & 22.5 & I & 0 & 0 & NA & NA & 0 & 11.7 \\
\hline 329 & GBM & 67 & 58.5 & I & 0 & 2 & NA & NA & NA & NA \\
\hline 321 & GBM & 69 & 24.571 & I & 0 & 0 & 0 & 0 & I & 46.9 \\
\hline 298 & GBM & 72 & 22.429 & I & 0 & 0 & 0 & 0 & 1 & 27.5 \\
\hline 309 & GBM & 76 & 29.429 & I & 0 & 0 & 0 & 0 & I & 91.9 \\
\hline 409 & GBM & 15 & $149.7 \mid 4$ & I & I & 2 & 2 & 0 & 3 & 25.4 \\
\hline 254 & GBM & 25 & |0|.57| & I & I & 2 & 2 & 0 & 3 & 34.8 \\
\hline 403 & GBM & 35 & 58 & I & I & 2 & 2 & 0 & I & 37.9 \\
\hline 192 & GBM & 51 & 36 & I & I & 1 & 2 & 0 & 1 & 31.7 \\
\hline 240 & GBM & 53 & 8.143 & I & I & 2 & 2 & 0 & 3 & 49.2 \\
\hline 124 & GBM & 54 & 46.143 & I & I & 2 & 2 & 0 & 1 & 41.7 \\
\hline 470 & GBM & 56 & 81 & I & I & 2 & NA & NA & 0 & 35.5 \\
\hline 408 & GBM & 57 & 44 & I & I & I & 2 & 0 & 1 & 32.8 \\
\hline 425 & GBM & 57 & 15.143 & I & I & 1 & 3 & 1 & 1 & 31.3 \\
\hline 279 & GBM & 59 & 47.143 & I & I & 2 & 3 & 1 & 2 & 23.4 \\
\hline 493 & GBM & 68 & 49.5 & I & I & 2 & NA & NA & NA & NA \\
\hline 471 & GBM & 70 & 42.286 & I & I & 1 & 3 & 2 & 0 & 25.5 \\
\hline 496 & GBM & 70 & 55.857 & I & I & I & 3 & 2 & 0 & 21.8 \\
\hline 245 & GBM & 70 & 22.5 & I & I & 2 & NA & NA & 2 & 22 \\
\hline 241 & GBM & 32 & 33.143 & I & 2 & 0 & 2 & 0 & 3 & 25.6 \\
\hline 261 & GBM & 33 & 21.571 & I & 2 & 2 & 2 & 0 & 2 & 50.1 \\
\hline 297 & GBM & 43 & |07.57| & I & 2 & 2 & 3 & 1 & 2 & 32.9 \\
\hline 323 & GBM & 46 & 81 & I & 2 & 2 & 2 & 0 & 1 & 16.9 \\
\hline 263 & GBM & 47 & 33.286 & I & 2 & 2 & 3 & 2 & 3 & 17.8 \\
\hline 90 & GBM & 48 & 66.857 & I & 2 & 1 & 3 & 2 & 1 & 15.4 \\
\hline 230 & GBM & 50 & $17.7 \mid 4$ & I & 2 & 2 & 2 & 0 & 1 & 35.8 \\
\hline 227 & GBM & 52 & 53.1429 & I & 2 & 2 & 3 & I & I & 43.1 \\
\hline 325 & GBM & 52 & 32.143 & I & 2 & 2 & 3 & 2 & 0 & 20.3 \\
\hline 443 & GBM & 55 & 59.286 & I & 2 & 1 & 3 & 2 & 1 & 39.7 \\
\hline
\end{tabular}


Table 2: A set of 6 I GBM specimens for analyses of patient survival and the correlation between FABP7 and EGFR expression

\begin{tabular}{|c|c|c|c|c|c|c|c|c|c|c|}
\hline 296 & GBM & 59 & 39 & $T$ & 2 & 0 & 2 & 0 & $T$ & 44.9 \\
\hline 335 & GBM & 75 & 18.143 & I & 2 & 2 & 2 & 0 & I & 27.5 \\
\hline
\end{tabular}

*Based on nuclear FABP7 and EGFR immunoreactivity: dual negative as "0", nuclear FABP7-/EGFR+ as "I", nuclear FABP7+/EGFR- as "2", and dual positive as "3"

$\mathrm{NA}$, no IHC data available.

\section{Epidermal growth factor treatment increases}

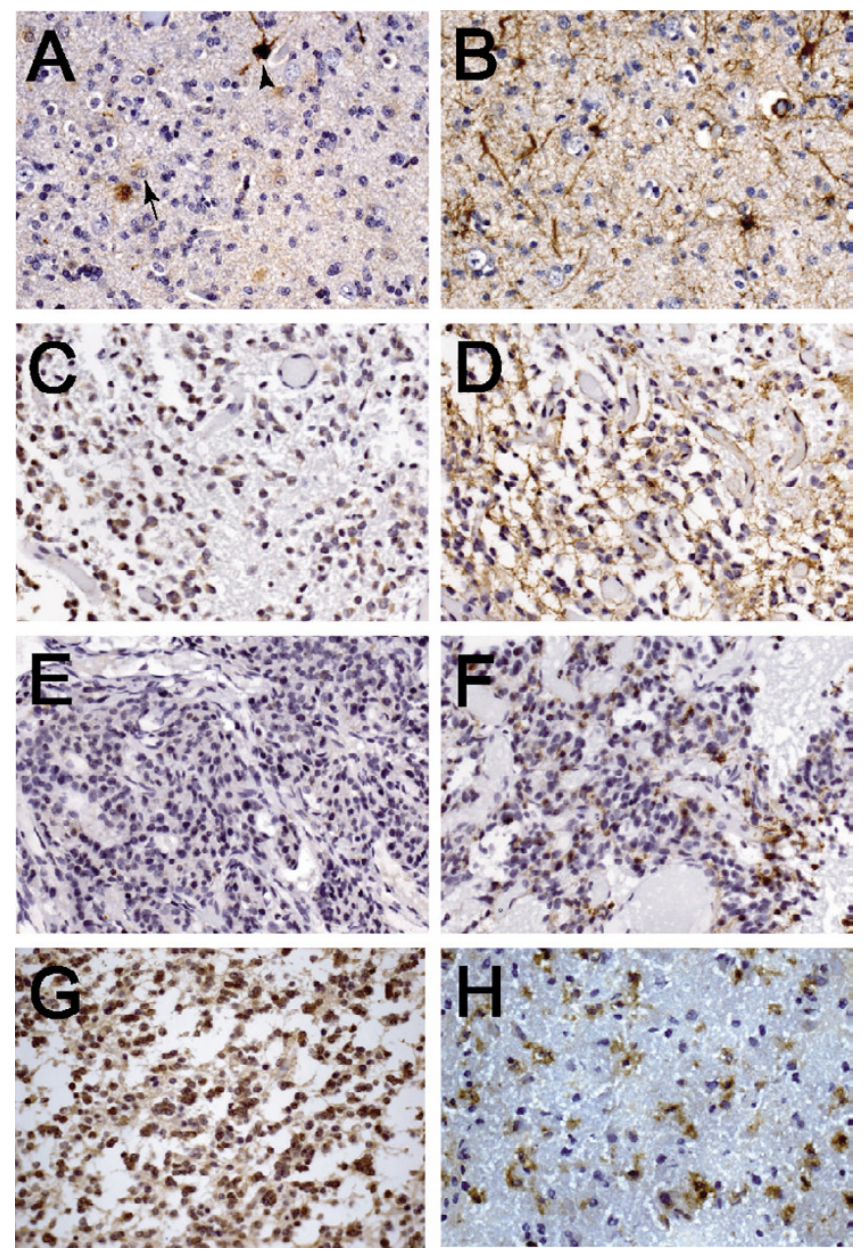

Figure 3

FABP7 is expressed in GFAP-positive cells in ODG and OAC. In grade III ODG, FABP7 $(A)$ was expressed only in a subset of reactive astrocytes resembling Types 3 (arrow) and 4 (arrowhead) cells when compared to numerous GFAPpositive cells in an adjacent section (B). FABP7 was expressed in both nuclei and cytoplasm of the microgemistocytes $(C)$ that were GFAP-immunoreactive $(D)$. However, some tumors with microgemistocytes clearly did not express detectable amount of FABP7 $(E)$ compared to GFAP $(F)$. FABP7 was also seen in both nuclei and cytoplasm of tumor cells in some grades II $(G)$ and III $(H)$ OAC, and adjacent sections showed that the same groups of cells were GFAP positive (data not shown). The scale of the photomicrographs is the same as in Figure I $A$. immunoreactivity of fatty acid-binding protein $\mathbf{7}$ in nucleus To investigate whether EGFR activation-induced FABP7 expression observed in Schwann cells [13] is present in GBM, we examined FABP7 expression and its subcellular localization upon EGFR activation. Four commonly used EGFR-expressing glioma cell lines, U87, U251, SF763, and SF767, were examined for FABP7 expression using immunohistochemistry, and all these lines demonstrated both cytoplasmic and nuclear FABP7 immunoreactivity (data not shown). The SF763 glioma cell line was chosen for this study because it had the lowest ratio of nuclear to cytoplasmic FABP7 as compared to other cell lines, and induction of FABP7 nuclear translocation by EGFR activation could be easily detected.

In SF7 63 cells, FABP7 expression increased after EGF treatment (Fig. 7A and 7B). To avoid artifacts caused by the heterogeneity of immunostaining or the increased expression of FABP7 after EGFR activation, the ratio of nuclear to cytoplasmic FABP7 immunoreactivity of each cell was calculated. The nuclear to cytoplasmic ratio of FABP7 staining in EGF-treated SF763 cells was statistically higher than in the group without EGF treatment $(\mathrm{p}<0.001$, Fig. $7 \mathrm{C})$, suggesting that nuclear translocation of FABP7 in GBM could be induced by EGFR activation.

\section{Epidermal growth factor-induced glioma cell migration is suppressed by inhibiting fatty acid binding protein 7 expression}

Since both EGFR activation [31] and forced expression of FABP7 [9] promote glioma cell migration, we examined whether inhibiting the expression of FABP7 can suppress glioma cell migration induced by EGF.

Antisense oligodeoxynucleotides (ODNs) have been successfully used to reduce expression of other members of the FABP family [32], so we examined whether inhibiting FABP7 expression with ODNs affects glioma cell migration. We found that FABP7-specific antisense ODNs suppressed more than one-third of EGF-induced SF763 cell migration, but had no effect on migration of the cells without EGF treatment (Fig. 7D). This result strongly suggests that at least a portion of EGF-induced glioma cell migration is mediated through FABP7.

\section{Discussion}

In previous work, we identified nuclear FABP7 immunoreactivity as a prognostic marker for patients with GBM 


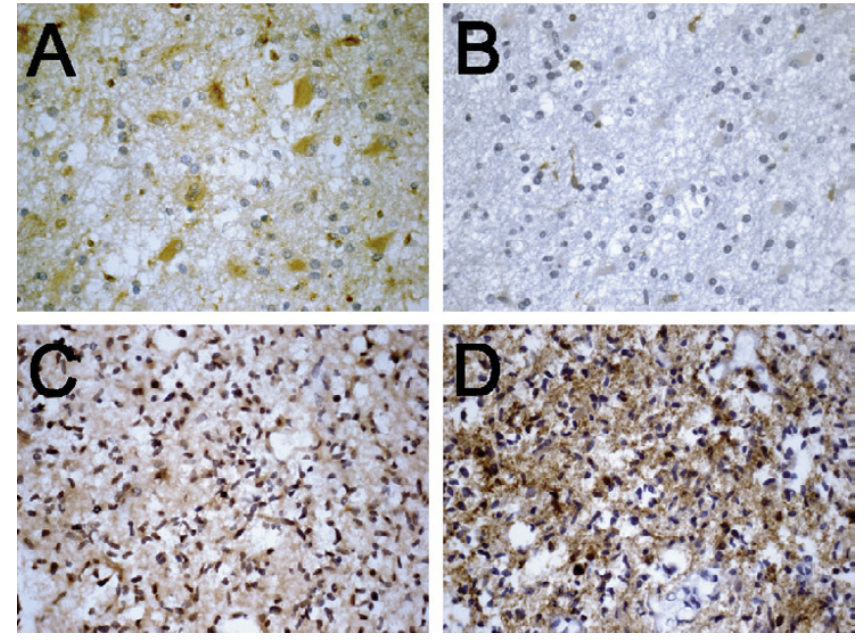

Figure 4

EGFR expression is associated with nuclear but not cytoplasmic FABP7 immunoreactivity. In one region of a representative GBM specimen, the cytoplasm of neoplastic gemistocytes had pronounced FABP7 immunoreactivity but the nuclei of the same cells were negative $(A)$. In an adjacent section of the same specimen only minimal EGFR staining was seen in the same population of tumor cells $(B)$. In another region of the same specimen, all nuclei of neoplastic astrocytes were marked by FABP7 staining (C), and EGFR expression was also prominent in these cells $(D)$. The scale of photomicrographs is the same as in Figure I $A$.

[9]. In a separate report, increased expression of FABP7 was also found in GBM patients surviving less than 2 years compared to those who survived longer [29]. Two cellular functions for FABP7 have been identified: cell migration and differentiation in the developing central nervous system [11], and Schwann cell-axonal interactions in the peripheral nervous system [13]. Although suggestive, neither offers a clear explanation of the action of FABP7 in gliomas. The goals of this study were to determine a plausible biological role for FABP7 in glioma pathogenesis. We characterize the expression of FABP7 in normal brain, gliotic tissues, and glial tumors. We show that increased FABP7 expression occurs in a subset of reactive astrocytes, that FABP7 expression is restricted to cells of astrocytic lineage in glioma, and that there is almost no nuclear FABP7 immunoreactivity in well-circumscribed pilocytic astrocytoma. In addition, we establish an association between nuclear FABP7 and EGFR expression both in human GBM tumors and in a glioma cell line. Our data suggest that FABP7 might play a role in GBM pathogenesis through its participation in the EGFR signaling pathways. Most importantly, we identify nuclear FABP7 immunoreactivity as a marker to predict the outcome of patients with EGFRpositive GBM.
Transcription of both FABP7 and EGFR genes showed marginal association based upon the microarray datasets, but only nuclear FABP7 immunoreactivity correlated with EGFR expression. Age is one of the most important prognostic factors for GBM patients, and it has been shown in separate studies that the status of EGFR expression is a better prognostic factor in younger patients $[7,33]$. Our data indicate that the prognostic value of nuclear FABP7 is also influenced by patient age [9]. However, the correlation between nuclear FABP7 and EGFR expression did not have preference to patient age in our study. Collectively, it appears that other factors (age is probably one of them, see below) yet to be identified participate in regulating the transcriptional and translational mechanisms shared by both FABP7 and EGFR genes, as well as in regulating the subcellular localizations of FABP7. This is compatible with the fact that EGFR expression and nuclear FABP7 immunoreactivity are mutually exclusive in a significant portion our clinical specimens. It will be pressing to define in the future why nuclear FABP7 is not present in some EGFR-positive GBM and whether other EGFR-
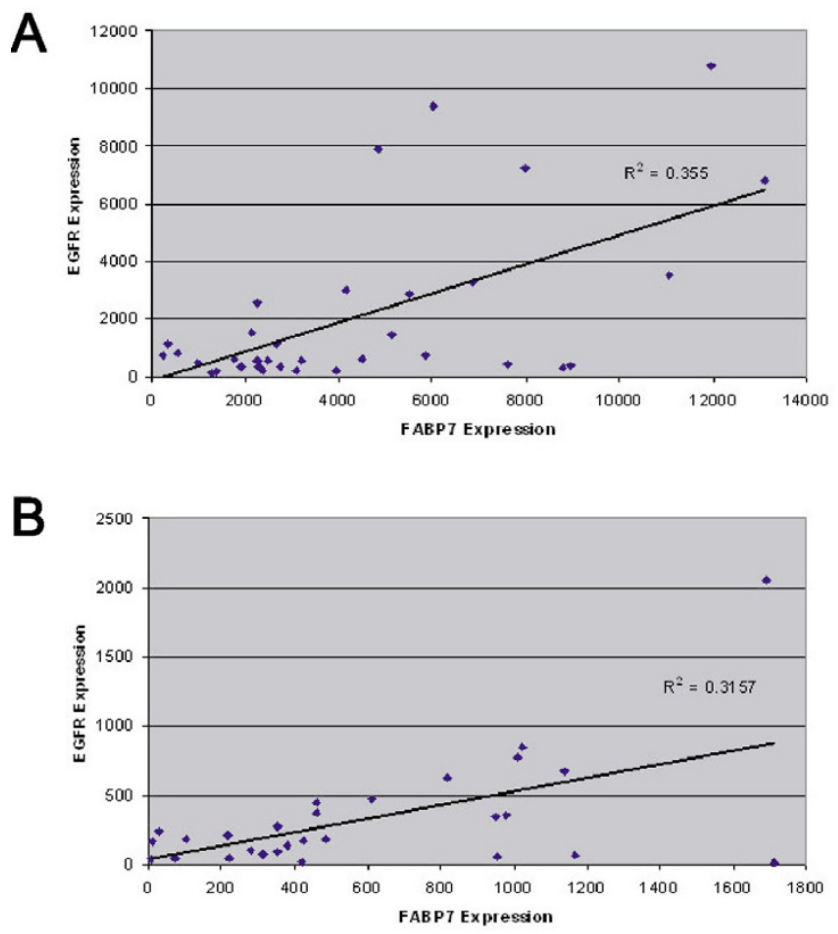

\section{Figure 5}

Scattered plot analyses of the expression levels of $F A B P 7$ and EGFR genes. The abundance of mRNA for both genes obtained by microarrays was presented on a log2 base. A strong positive correlation of FABP7 and EGFR expression was seen in a set of $34 \mathrm{GBM}$ specimens $(A, p=0.016)$, which was validated by a public microarray dataset using $28 \mathrm{GBM}$ specimens $(B, p=0.03)$. 

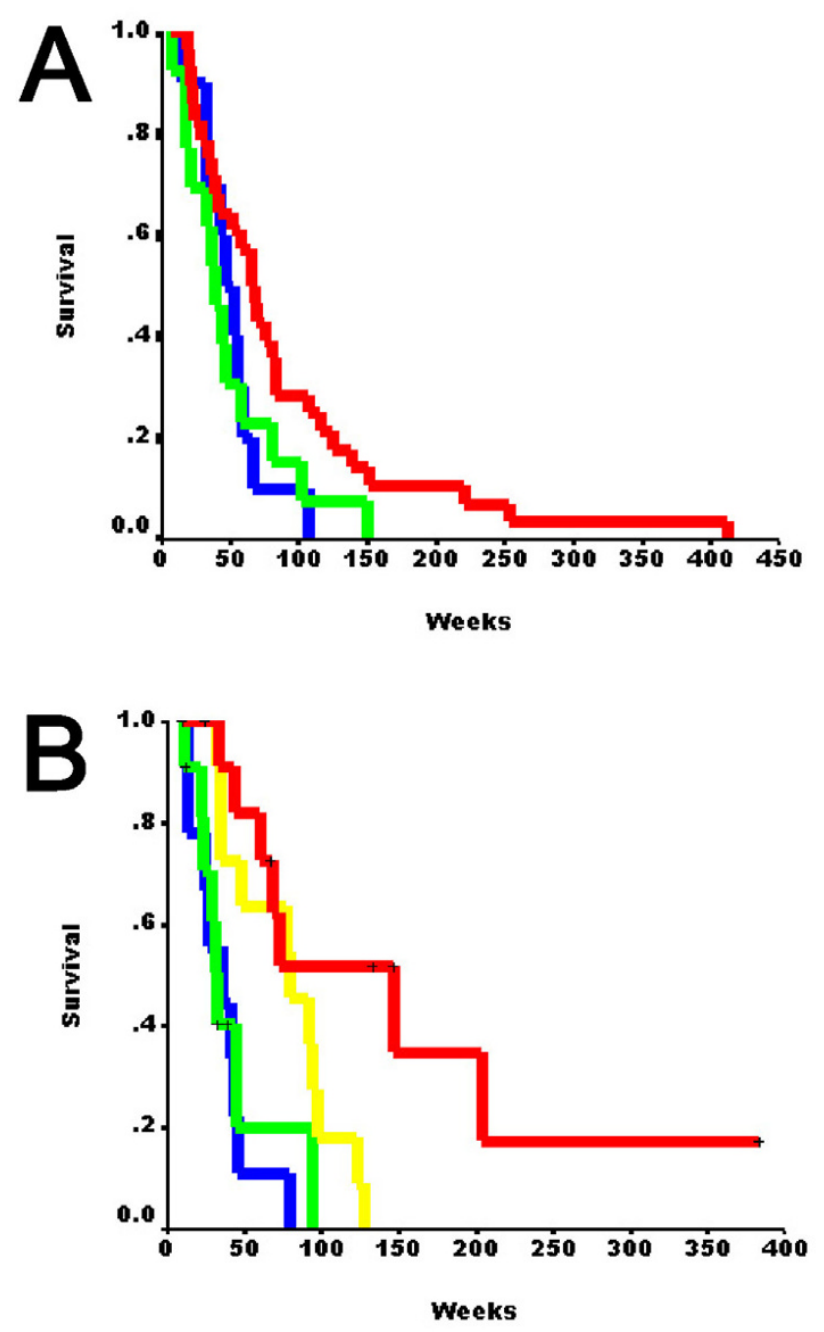

Figure 6

Kaplan-Meier analysis of the first set of 55 GBM patients based on the new categories $(0, N=28 ; I, N=4 ; 2, N=13$; $3, \mathrm{~N}=10$ ) of nuclear FABP7 and EGFR expression (see Methods) showed that dual-negative specimens had significant longer survival time $(A)$. Kaplan-Meier analysis of an independent set of 44 younger GBM patients $(0, \mathrm{~N}=\mathrm{I} \mathrm{I}$; I, $\mathrm{N}$ $=12 ; 2, \mathrm{~N}=1 \mathrm{I} ; 3, \mathrm{~N}=10$ ) showed gradual decrease of survival time based on increased expression of nuclear FABP7 and EGFR (B). Red, category 0; yellow, category I; green, category 2; blue, category 3.

downstream pathways are active in EGFR-negative/ nuclear FABP7-positive tumors.

It has been previously reported that EGFR signaling induces FABP7 expression in a Ras-independent pathway in normal and tumor Schwann cells [13], providing evidence of possible interaction between these two proteins. Our demonstration in GBM specimens that expression of both FABP7 and EGFR correlated with each other at both protein and mRNA levels, and in SF763 glioma cells that EGFR activation induced nuclear translocation of FABP7, warrants further investigation of whether FABP7 is a direct downstream target of EGFR activation in GBM and which EGFR pathway FABP7 is associated with. It has been
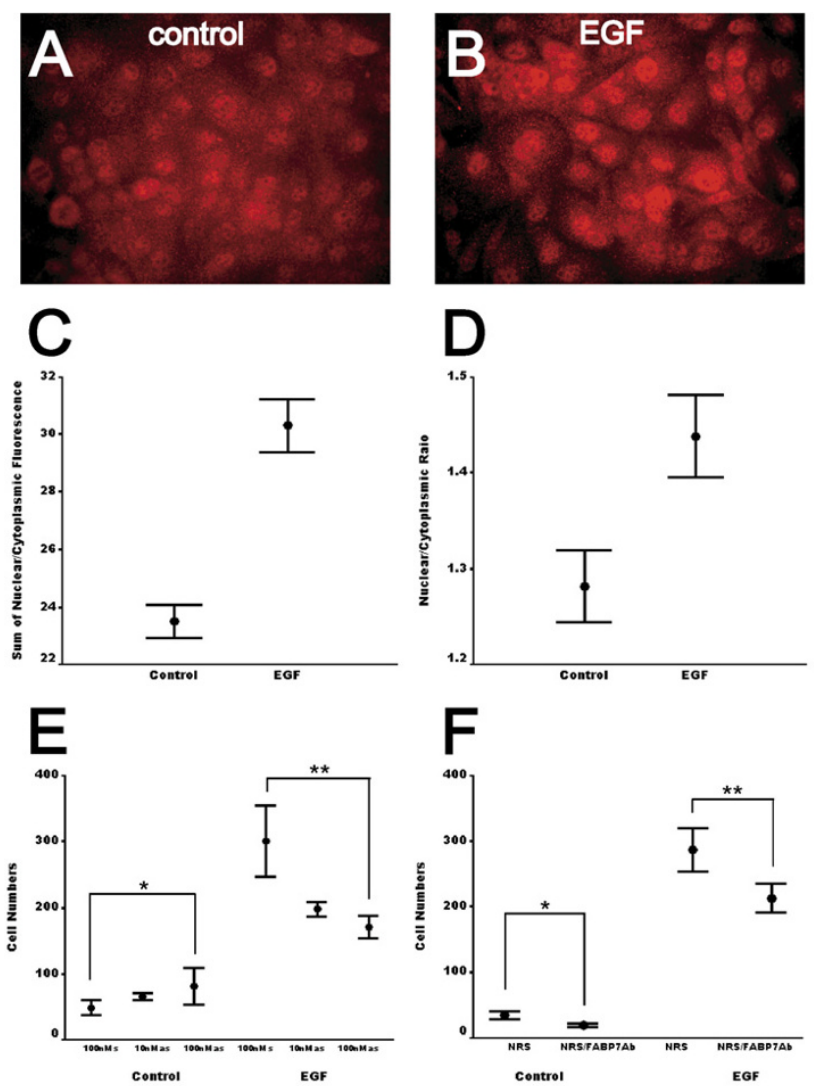

\section{Figure 7}

EGF activation induces nuclear translocation of FABP7 in glioma cells. Immunofluorescent staining of FABP7 in SF763 glioma cells displayed both cytoplasmic and nuclear immunoreactivity $(A)$, whereas FABP7 staining in the nuclei was increased after EGF treatment for 2 days $(B)$. The scale of photomicrographs is the same as in Figure IA. $C$, the sum of nuclear and cytoplasmic FABP7 fluorescence in SF763 cells in each of the 10 randomly chosen fields was calculated, and EGF treatment significantly increased total FABP7 fluorescence. $D$, the ratios of nuclear/cytoplasmic FABP7 in untreated SF763 glioma cells and cells treated with $50 \mathrm{ng} / \mathrm{ml}$ of EGF for I day were semi-quantitatively measured. For each group, ratios of 20 cells were calculated from each of the 10 randomly chosen fields $(p<0.001)$. $E$, control SF763 cells demonstrated no difference in migration in the presence of either FABP7-specific sense or antisense ODNs (*, $p=$ 0.136), whereas migration of EGF-treated SF763 cells was reduced by more than one-third in the presence of antisense ODNs (**, $p=0.004)$. F, FABP7 polyclonal antibodies also inhibited migration of both control and EGF-treated SF763 cells $(*, p=0.003 ; * *, p=0.01)$. Error bars represented the standard errors of the mean. 
shown that liver-type FABP carries fatty acids to interact with nuclear receptors that in turn regulate gene expression [22-24]. If FABP7 utilizes a similar mechanism to regulate gene expression in response to EGFR activation, this would expand the scope of EGFR signaling pathways in GBM tumors. Future studies will examine the specific molecular pathways linking EGFR and FABP7, and nuclear functions of FABP7.

In normal cerebral cortex, we identify a unique population of glia positive for FABP7 but negative for GFAP that we designated as Type 1 cells. The origin and exact role of these cells remains unclear. NG2, a chondroitin sulfate proteoglycan, is expressed by oligodendrocyte progenitors, and identification of one type of GFAP-negative/ NG2-positive astrocytes in adult normal brain and a subset of gliomas led to a hypothesis that certain gliomas arise from the NG2-positive progenitor cells [34]. According to the morphology and frequency of appearance [35], Type 1 cells identified in this study clearly do not belong to this category. However, based upon the expression patterns of FABP7 during the development of central nervous system, in adult brain, and in gliomas, transformation of FABP7-positive cells may contribute to the histogenesis of a subgroup of gliomas.

In gliotic brain tissue, FABP7 expression is increased in a subset of reactive astrocytes and demonstrates variable subcellular localization in the cytoplasm and nucleus. Such differential patterns in both expression and subcellular localization of FABP7 are also seen in cells with astrocytic features in various types of glioma. As noted above, grade I pilocytic astrocytoma is the only type of glioma examined that does not show nuclear FABP7 staining in our studies. Although our size of sampling was limited, the statistical analyses clearly demonstrate that the chance of detecting nuclear FABP7 in pilocytic astrocytoma is small. Because pilocytic astrocytomas are well-demarcated lesions whose pattern of growth is clearly distinctive from diffusely infiltrative higher-grade (grades II to IV) astrocytoma and oligodendroglial tumors (both ODG and $\mathrm{OAC}$ ), considering the association of nuclear FABP7 with poor prognosis of GBM patients, cytoplasmic localization of FABP7 may be associated with less infiltrative phenotype of neoplastic astrocytes. Interestingly, we did find positive correlation between cytoplasmic FABP7 immunoreactivity and patient survival in cases older than the medium age among the first set of 61 GBM specimens (data not shown), although this observation has not been validated in an independent set of samples. It would be important in the future to investigate the downstream signaling pathways for FABP7 in the nucleus and cytoplasm and their association with cell motility, and how the translocation of FABP7 is regulated, especially under the context of patient age.
Although FABP7 expression does not predict the outcome of patients with ODG and OAC [36], FABP7 may have prognostic value for grade II and grade III astrocytomas due to its heterogeneous patterns of expression and subcellular localization in these two tumor types. In other experiments, we noted that immortalized non-tumorigenic astrocytes express similar amounts of FABP7 compared to glioma cell lines (data not shown). FABP7 overexpression in glioma cells does not affect cell cycle progression and activation of apoptosis [9]. In gliotic brain tissue increased FABP7 expression coincides with GFAP expression in a subset of reactive astrocytes. Increased expression of FABP7 was seen in brain tissues after systematic administration of a neurotoxin, kainic acid [14]. FABP7 was released into patients' serum after acute ischemic stroke [37]. For these reasons, FABP7 expression or the presence of nuclear FABP7 alone is unlikely a factor unique to glioma oncogenesis and progression. On a practical level, however, anecdotal experience suggests that occasional cases exist where the main differential diagnosis is pilocytic astrocytoma versus GBM (both of these astrocytic tumors exhibit microvascular proliferation), and the presence of nuclear FABP7 wouldsupport the diagnosis of GBM.

In addition to this report, elevated levels of FABP7 mRNA and protein in GBM specimens compared to those in normal adult brain have been previously demonstrated $[9,12]$. Opposite results were reported in breast and prostate cancer, where decreased expression of FABP7 was found in tumor specimens when compared to normal tissues [19,32]. Greater FABP7 expression was seen in rarely metastasized melanoma cell lines compared to their frequently metastasizing counterparts [38]. Poorly-differentiated prostate tumors lose FABP7 expression, but more FABP7 is expressed in well-differentiated prostate cancer specimens than in primary normal prostate cells [32]. Ectopic expression of FABP7 induces cell differentiation and suppresses tumor growth $[19,20]$ and was shown to mediate the cytotoxicity of DHA to breast cancer cells [20]. One explanation for these divergent results in patterns of expression and effects of forced expression is that functions of FABP7 in neoplastic and normal cells are tissue-specific. A strong candidate factor involved in such tissue-specific functions is EGFR, since we observed in clinical specimens the correlation of gene expression between FABP7 and EGFR, and the correlation of nuclear FABP7 immunoreactivity with EGFR expression; however, this association appears to be only in GBM, but not in normal brain, gliotic tissues, or other types of glioma examined.

Our immunohistochemical results show the change of subcellular localization of FABP7 in normal, gliotic, and neoplastic brain tissues and suggest several interesting 
Table 3: Expression of FABP7 and EGFR mRNA in GBM from two independent published DNA microarray datasets

\begin{tabular}{|c|c|c|c|c|c|}
\hline \multicolumn{3}{|c|}{ Dataset I (ref. 29) } & \multicolumn{3}{|c|}{ Dataset 2(ref. 30) } \\
\hline Case \# & FABP7 & EGFR & Case \# & FABP7 & EGFR \\
\hline 47.0 & 227.5 & 763.5 & 1375 & 28.8 & 233.8 \\
\hline 210.4 & 337.0 & 1113.8 & 276 & 1010.0 & 775.2 \\
\hline 193.0 & 555.6 & 831.6 & 519 & 72.1 & 46.7 \\
\hline 21.7 & 974.6 & $47 \mathrm{I} .4$ & 368 & 418.2 & 14.7 \\
\hline 97.3 & 1277.9 & 146.0 & 157 & 6.3 & 35.2 \\
\hline 147.9 & 1384.4 & 188.3 & 1162 & 378.0 & 139.9 \\
\hline 365.0 & I758.| & 625.4 & 1644 & 9.8 & 165.8 \\
\hline 131.7 & 1908.4 & 367.4 & 406 & 950.8 & 341.8 \\
\hline 459.4 & 2126.0 & 1522.5 & 308 & 611.3 & 473.7 \\
\hline 33.9 & 2246.2 & 2588.0 & 177 & 817.8 & 630.8 \\
\hline 58.7 & 2250.7 & 558.9 & 103 & 313.2 & 74.4 \\
\hline 158.0 & 2289.3 & 327.5 & 992 & 1024.3 & 842.2 \\
\hline 22.3 & 2351.9 & 224.2 & 41 & 952.3 & 56.6 \\
\hline 97.9 & 2480.0 & 578.6 & 1354 & 101.3 & 182.9 \\
\hline 14.0 & 2662.4 & 1134.1 & 308 & 424.0 & 169.2 \\
\hline 205.9 & 2746.3 & 357.6 & 408 & 279.7 & 97.3 \\
\hline 232.0 & 3071.7 & 220.9 & 242 & 1137.2 & 673.9 \\
\hline 226.6 & 3190.2 & 547.5 & 323 & 218.8 & 208.4 \\
\hline 29.4 & 3944.2 & 196.8 & 213 & 219.6 & 49.0 \\
\hline 68.0 & 4158.9 & 3010.9 & 97 & 352.8 & 87.4 \\
\hline 5.3 & 4496.3 & 625.6 & 281 & 978.6 & 357.0 \\
\hline 31.1 & 4831.9 & 7883.7 & 501 & 1166.7 & 64.5 \\
\hline 83.0 & 5120.5 & 1440.0 & 670 & $46 I .1$ & 444.7 \\
\hline 80.0 & 5508.2 & 2871.1 & 729 & 1711.5 & 8.9 \\
\hline 82.0 & 5854.7 & 741.7 & 21 & 1690.3 & 2057.1 \\
\hline 103.6 & 6008.9 & 9373.4 & 630 & 353.7 & 274.0 \\
\hline 2.6 & 6850.0 & 3259.5 & 263 & 460.3 & 375.6 \\
\hline 41.3 & 7593.1 & 441.2 & 219 & 486.4 & 179.7 \\
\hline 60.9 & 7966.5 & 7258.6 & & & \\
\hline 46.1 & 8795.5 & 284.8 & & & \\
\hline 40.3 & 8946.3 & 410.0 & & & \\
\hline 58.3 & I I070.| & 3518.5 & & & \\
\hline 50.4 & I 1956.1 & 10788.3 & & & \\
\hline 16.3 & 13108.3 & 6798.5 & & & \\
\hline
\end{tabular}

avenues for future studies. Based on its amino acid sequence and protein structure, the primary activity of FABP7 appears to be binding of fatty acids. Although the binding affinity of FABP7 for various types of long-chain fatty acids has been studied in vitro, and a likely in vivo ligand for FABP7 has been proposed [15], the actual fatty acids bound to FABP7 are yet to be determined. Because FABP7 does not possess an obvious nuclear localization signal, nuclear translocation of FABP7 might require other carrier proteins. Defining these interacting proteins and ligands should clarify the biological roles of FABP7.

\section{Conclusion}

FABP7 is preferentially expressed in cells of astrocytic features, and demonstrates variable expression levels and subcellular localization in gliotic tissues and all grades of astrocytoma, indicating that FABP7 expression alone does not contribute to malignant progression of astrocytomas.
However, nuclear localization of FABP7 may be associated with infiltrative phenotype of glioma cells and EGFR pathways based on several findings: correlation of nuclear FABP7 immunoreactivity with poor prognosis of younger patients with GBM, association with EGFR expression in GBM, lack of nuclear FABP7 immunoreactivity in grade I astrocytomas, and induction of translocation of FABP7 into nucleus in glioma cells after EGFR activation.

\section{Abbreviations}

FABP7, brain-type fatty acid-binding protein; GBM, glioblastoma; EGFR, epidermal growth factor receptor; DHA, docosahexaenoic acid; GFAP, glial fibrillary acidic protein; ODN, oligodeoxynucleotide; $\mathrm{CI}$, confidence interval.

\section{Competing interests}

The author(s) declare that they have no competing interests. 
Table 4: An independent set of 44 GBM specimens to examine the effects of nuclear FABP7 and EGFR expression on patient survival

\begin{tabular}{|c|c|c|c|c|c|c|c|}
\hline Case \# & Diagnosis & Age & Survival (wk) & Censor & FABP7 Nu & EGFR IHC & New Category* \\
\hline 17 & GBM & 54.2 & 73.2 & 1 & 0 & 0 & 0 \\
\hline 30 & GBM & 24.3 & 203.9 & I & 0 & 0 & 0 \\
\hline 45 & GBM & 45.2 & 67.9 & I & 0 & 0 & 0 \\
\hline 46 & GBM & 26.9 & 146.7 & 0 & 0 & 0 & 0 \\
\hline 66 & GBM & 17.5 & 133.5 & 0 & 0 & 0 & 0 \\
\hline 68 & GBM & 31.6 & 146.9 & I & 0 & 0 & 0 \\
\hline 81 & GBM & 51.1 & 60.6 & I & 0 & 0 & 0 \\
\hline 84 & GBM & 43.6 & 66.8 & 0 & 0 & 0 & 0 \\
\hline 87 & GBM & 59.9 & 43.4 & I & 0 & 0 & 0 \\
\hline 91 & GBM & 46.4 & 383.0 & 0 & 0 & 0 & 0 \\
\hline 94 & GBM & 54.0 & 33.7 & I & 0 & 0 & 0 \\
\hline 98 & GBM & 39.1 & 48.6 & I & 0 & I & I \\
\hline 99 & GBM & 56.9 & 128.1 & I & 0 & I & I \\
\hline 107 & GBM & 59.1 & 79.8 & I & 0 & 2 & I \\
\hline 110 & GBM & 45.2 & 35.1 & I & 0 & 2 & I \\
\hline 148 & GBM & 59.8 & 35.1 & I & 0 & 2 & 1 \\
\hline 194 & GBM & 54.8 & 32.7 & I & 0 & 2 & I \\
\hline 225 & GBM & 54.1 & 94.3 & I & 0 & 2 & I \\
\hline 243 & GBM & 50.6 & 76.8 & I & 0 & 2 & 1 \\
\hline 263 & GBM & 54.7 & 123.1 & I & 0 & 2 & I \\
\hline 277 & GBM & 42.5 & 25.1 & 0 & 0 & 2 & I \\
\hline 284 & GBM & 47.7 & 92.3 & I & 0 & 2 & I \\
\hline 29 & GBM & 35.3 & 97.0 & I & 0 & 2 & I \\
\hline 89 & GBM & 55.2 & 45.1 & I & I & 0 & 2 \\
\hline 273 & GBM & 42.5 & 39.0 & 0 & 1 & 0 & 2 \\
\hline 4 & GBM & 51.0 & 29.5 & I & 1 & 0 & 2 \\
\hline 21 & GBM & 59.3 & 32.7 & I & I & 0 & 2 \\
\hline 32 & GBM & 58.2 & 22.1 & I & I & 0 & 2 \\
\hline 53 & GBM & 51.2 & 23.8 & 1 & 2 & 0 & 2 \\
\hline 54 & GBM & 33.1 & 32.7 & 0 & 2 & 0 & 2 \\
\hline 58 & GBM & 37.2 & 31.1 & I & 2 & 0 & 2 \\
\hline 61 & GBM & 12.8 & 12.3 & 0 & 2 & 0 & 2 \\
\hline 88 & GBM & 52.2 & 93.9 & 1 & 2 & 0 & 2 \\
\hline 100 & GBM & 45.8 & 11.3 & I & 2 & 0 & 2 \\
\hline 103 & GBM & 55.1 & 13.9 & I & 2 & 2 & 3 \\
\hline 105 & GBM & 41.7 & 46.1 & I & 2 & 2 & 3 \\
\hline 106 & GBM & 43.8 & 10.5 & 0 & 2 & 2 & 3 \\
\hline 207 & GBM & 51.3 & 27.1 & I & 2 & 2 & 3 \\
\hline 240 & GBM & 45.2 & 13.3 & I & 2 & 2 & 3 \\
\hline 247 & GBM & 58.7 & 43.3 & 1 & 2 & 2 & 3 \\
\hline 265 & GBM & 58.8 & 80.1 & I & 2 & 2 & 3 \\
\hline 34 & GBM & 54.4 & 36.0 & I & I & I & 3 \\
\hline 38 & GBM & 23.0 & 24.1 & 1 & I & 2 & 3 \\
\hline 50 & GBM & 25.0 & 41.0 & 1 & I & 2 & 3 \\
\hline
\end{tabular}

*Based on nuclear FABP7 and EGFR immunoreactivity: dual negative as "0", nuclear FABP7-/EGFR+ as "I", nuclear FABP7+/EGFR- as "2", and dual positive as " 3 "

\section{Authors' contributions}

YL designed the study, performed the experiments, analyzed the data, and wrote the manuscript. AWB and KDA participated in evaluating the histopathology and immunohistochemistry of the specimens. NG participated in analyzing the data and critically editing the manuscript. All authors read and approved the final version of the manuscript.

\section{Acknowledgements}

We thank the Neurosurgery Tissue Bank of UCSF for contributing tissue specimens in this study. We would also like to thank Dr. Nathaniel Heintz for providing FABP7 antiserum. We are grateful to Dr. Dennis Deen for critically reading and commenting on the manuscript. This work was supported by funding from the Department of Neurological Surgery at UCSF. UCSF is an NCl-designated Specialized Program of Research Excellence for Brain Tumors. 


\section{References}

I. Medical Research Council Brain Tumor Working Party: Randomized trial of procarbazine, lomustine, and vincristine in the adjuvant treatment of high-grade astrocytoma: a Medical Research Council trial. J Clin Oncol 200I, I9(2):509-5I8.

2. Korkolopoulou P, Christodoulou P, Kouzelis K, Hadjiyannakis M, Priftis A, Stamoulis G, Seretis A, Thomas-Tsagli E: MDM2 and p53 expression in gliomas: a multivariate survival analysis including proliferation markers and epidermal growth factor receptor. $\mathrm{Br}$ J Cancer I997, 75(9): | 269-1278.

3. Etienne MC, Formento JL, Lebrun-Frenay C, Gioanni J, Chatel M Paquis P, Bernard C, Courdi A, Bensadoun RJ, Pignol JP, Francoual M, Grellier P, Frenay M, Milano G: Epidermal growth factor receptor and labeling index are independent prognostic factors in glial tumor outcome. Clin Cancer Res 1998, 4(1 0):2383-2390.

4. Rainov NG, Dobberstein KU, Bahn H, Holzhausen HJ, Lautenschlager C, Heidecke V, Burkert W: Prognostic factors in malignant glioma: influence of the overexpression of oncogene and tumor-suppressor gene products on survival. I Neurooncol I997, 35(I): I3-28.

5. Waha A, Baumann A, Wolf HK, Fimmers R, Neumann J, Kindermann D, Astrahantseff K, Blumcke I, von Deimling A, Schlegel U: Lack of prognostic relevance of alterations in the epidermal growth factor receptor-transforming growth factor-alpha pathway in human astrocytic gliomas. J Neurosurg 1996, 85(4):634-64I.

6. Newcomb EW, Cohen H, Lee SR, Bhalla SK, Bloom J, Hayes RL, Miller DC: Survival of patients with glioblastoma multiforme is not influenced by altered expression of p I6, p53, EGFR, MDM2 or Bcl-2 genes. Brain Pathol 1998, 8(4):655-667.

7. Simmons ML, Lamborn KR, Takahashi M, Chen P, Israel MA, Berger MS, Godfrey T, Nigro J, Prados M, Chang S, Barker FG 2nd, Aldape $\mathrm{K}$ : Analysis of complex relationships between age, p53, epidermal growth factor receptor, and survival in glioblastoma patients. Cancer Res 200 I, 6 I (3): I I22-II28.

8. Batchelor TT, Betensky RA, Esposito JM, Pham LD, Dorfman MV, Pis catelli N, Jhung S, Rhee D, Louis DN: Age-dependent prognostic effects of genetic alterations in glioblastoma. Clin Cancer Res 2004, I O(I Pt I):228-233.

9. Liang $Y$, Diehn M, Watson N, Bollen AW, Aldape KD, Nicholas MK, Lamborn KR, Berger MS, Botstein D, Brown PO, Israel MA: Gene expression profiling reveals molecularly and clinically distinct subtypes of glioblastoma multiforme. Proc Natl Acad Sci U S A 2005, 102(16):5814-5819.

10. Diehn M, Sherlock G, Binkley G, Jin H, Matese JC, Hernandez-Boussard T, Rees CA, Cherry JM, Botstein D, Brown PO, Alizadeh AA: SOURCE: a unified genomic resource of functional annotations, ontologies, and gene expression data. Nucleic Acids Res 2003, 3 I(I):219-223.

II. Feng L, Hatten ME, Heintz N: Brain lipid-binding protein (BLBP): a novel signaling system in the developing mammalian CNS. Neuron 1994, I 2(4):895-908.

12. Godbout R, Bisgrove DA, Shkolny D, Day RS 3rd: Correlation of BFABP and GFAP expression in malignant glioma. Oncogene 1998, I6(I5): 1955-1962.

13. Miller SJ, Li H, Rizvi TA, Huang Y, Johansson G, Bowersock J, Sidan A, Vitullo J, Vogel K, Parysek LM, DeClue JE, Ratner N: Brain lipid binding protein in axon-Schwann cell interactions and peripheral nerve tumorigenesis. Mol Cell Biol 2003 , 23(6):22 I 3-2224.

14. Owada $\mathrm{Y}$, Yoshimoto $\mathrm{T}$, Kondo $\mathrm{H}$ : Increased expression of the mRNA for brain- and skin-type but not heart-type fatty acid binding proteins following kainic acid systemic administration in the hippocampal glia of adult rats. Brain Res Mol Brain Res 1996, 42(I): I56-160.

15. Xu LZ, Sanchez R, Sali A, Heintz N: Ligand specificity of brain lipid-binding protein. JBiol Chem 1996, 27 I(40):247| I-247I9.

16. Feng $L$, Heintz N: Differentiating neurons activate transcription of the brain lipid-binding protein gene in radial glia through a novel regulatory element. Development 1995, I 2 I(6): I7|9-1730.

17. Shimizu F, Watanabe TK, Shinomiya H, Nakamura $Y$, Fujiwara T: Isolation and expression of a cDNA for human brain fatty acidbinding protein (B-FABP). Biochim Biophys Acta 1997, I 354(I):24-28.

18. Khan SH, Sorof S: Liver fatty acid-binding protein: specific mediator of the mitogenesis induced by two classes of carci- nogenic peroxisome proliferators. Proc Natl Acad Sci U S A 1994, 9 I (3):848-852

19. Shi YE, Ni J, Xiao G, Liu YE, Fuchs A, Yu G, Su J, Cosgrove JM, Xing L, Zhang M, Li J, Aggarwal BB, Meager A, Gentz R: Antitumor activity of the novel human breast cancer growth inhibitor, mammary-derived growth inhibitor-related gene, MRG. Cancer Res | 997, 57( I 5):3084-309|.

20. Wang M, Liu YE, Ni J, Aygun B, Goldberg ID, Shi YE: Induction of mammary differentiation by mammary-derived growth inhibitor-related gene that interacts with an omega-3 fatty acid on growth inhibition of breast cancer cells. Cancer Res 2000, 60(22):6482-6487.

21. Glatz JF, Luiken JJ, van Bilsen M, van der Vusse GJ: Cellular lipid binding proteins as facilitators and regulators of lipid metabolism. Mol Cell Biochem 2002, 239(I-2):3-7.

22. Wolfrum C, Borrmann CM, Borchers T, Spener F: Fatty acids and hypolipidemic drugs regulate peroxisome proliferator-activated receptors alpha - and gamma-mediated gene expression via liver fatty acid binding protein: a signaling path to the nucleus. Proc Natl Acad Sci U S A 200I, 98(5):2323-2328.

23. Huang $H$, Starodub $O$, Mclntosh A, Kier AB, Schroeder F: Liver fatty acid-binding protein targets fatty acids to the nucleus. Real time confocal and multiphoton fluorescence imaging in living cells. J Biol Chem 2002, 277(32):29139-29I5I.

24. Huang $H$, Starodub $O$, Mclntosh A, Atshaves BP, Woldegiorgis G, Kier AB, Schroeder F: Liver fatty acid-binding protein colocalizes with peroxisome proliferator activated receptor alpha and enhances ligand distribution to nuclei of living cells. Biochemistry 2004, 43(9):2484-2500.

25. Abdelwahab SA, Owada $Y$, Kitanaka N, Iwasa $H$, Sakagami $H$, Kondo $\mathrm{H}$ : Localization of brain-type fatty acid-binding protein in Kupffer cells of mice and its transient decrease in response to lipopolysaccharide. Histochem Cell Biol 2003, I I 9(6):469-475.

26. Sonoda Y, Ozawa T, Hirose Y, Aldape KD, McMahon M, Berger MS Pieper RO: Formation of intracranial tumors by genetically modified human astrocytes defines four pathways critical in the development of human anaplastic astrocytoma. Cancer Res 200I, 6 I ( I 3):4956-4960.

27. Kurtz A, Zimmer A, Schnutgen F, Bruning G, Spener F, Muller T: The expression pattern of a novel gene encoding brain-fatty acid binding protein correlates with neuronal and glial cell development. Development 1994, I 20(9):2637-2649.

28. Gutmann DH, Hedrick NM, Li J, Nagarajan R, Perry A, Watson MA: Comparative gene expression profile analysis of neurofibromatosis I-associated and sporadic pilocytic astrocytomas. Cancer Res 2002, 62(7):2085-209I.

29. Nigro JM, Misra A, Zhang L, Smirnov I, Colman H, Griffin C, Ozburn N, Chen M, Pan E, Koul D, Yung WK, Feuerstein BG, Aldape KD: Integrated array-comparative genomic hybridization and expression array profiles identify clinically relevant molecular subtypes of glioblastoma. Cancer Res 2005, 65(5):|678-| 686.

30. Nutt CL, Mani DR, Betensky RA, Tamayo P, Cairncross JG, Ladd C, Pohl U, Hartmann C, McLaughlin ME, Batchelor TT, Black PM, von Deimling A, Pomeroy SL, Golub TR, Louis DN: Gene expressionbased classification of malignant gliomas correlates better with survival than histological classification. Cancer Res 2003, 63(7): 1602-1607

31. Lund-Johansen M, Bjerkvig R, Humphrey PA, Bigner SH, Bigner DD, Laerum OD: Effect of epidermal growth factor on glioma cell growth, migration, and invasion in vitro. Cancer Res 1990 , 50( I 8):6039-6044.

32. Das R, Hammamieh R, Neill R, Melhem M, Jett M: Expression pattern of fatty acid-binding proteins in human normal and cancer prostate cells and tissues. Clin Cancer Res 200I, 7(6): $|706-| 7 \mid 5$.

33. Shinojima N, Tada K, Shiraishi S, Kamiryo T, Kochi M, Nakamura H, Makino K, Saya H, Hirano H, Kuratsu J, Oka K, Ishimaru Y, Ushio Y: Prognostic value of epidermal growth factor receptor in patients with glioblastoma multiforme. Cancer Res 2003, 63(20):6962-6970.

34. Shoshan Y, Nishiyama A, Chang A, Mork S, Barnett GH, Cowell JK, Trapp BD, Staugaitis SM: Expression of oligodendrocyte progenitor cell antigens by gliomas: implications for the histogenesis of brain tumors. Proc Natl Acad Sci $U$ S A 1999, 96( I 8): $1036 \mid-10366$ 
35. Nishiyama A, Chang A, Trapp BD: NG2+ glial cells: a novel glial cell population in the adult brain. J Neuropathol Exp Neurol 1999, 58(II):III3-III24.

36. Liang Y, Bollen AW, Nicholas K, Gupta N: Id4 and FABP7 are preferentially expressed in cells with astrocytic features in oligodendrogliomas and oligoastrocytomas. BMC Clin Pathol 2005, 5(I):6.

37. Wunderlich MT, Hanhoff T, Goertler M, Spener F, Glatz JF, Wallesch CW, Pelsers MM: Release of brain-type and heart-type fatty acid-binding proteins in serum after acute ischaemic stroke. J Neurol 2005, 252(6):718-724.

38. de Wit NJ, Rijntjes J, Diepstra JH, van Kuppevelt TH, Weidle UH, Ruiter DJ, van Muijen GN: Analysis of differential gene expression in human melanocytic tumour lesions by custom made oligonucleotide arrays. Br J Cancer 2005, 92(I2):2249-226I.

\section{Pre-publication history}

The pre-publication history for this paper can be accessed here:

http://www.biomedcentral.com/1471-2407/6/97/prepub

Publish with Biomed Central and every scientist can read your work free of charge

"BioMed Central will be the most significant development for disseminating the results of biomedical research in our lifetime. "

Sir Paul Nurse, Cancer Research UK

Your research papers will be:

- available free of charge to the entire biomedical community

- peer reviewed and published immediately upon acceptance

- cited in PubMed and archived on PubMed Central

- yours - you keep the copyright

Submit your manuscript here:

http://www.biomedcentral.com/info/publishing_adv.asp 